\title{
A Note: Constant Market Share Analysis
}

\section{Graziella Bonanno*}

Department of Economics, Statistics and Finance, University of Calabria, Italy

\begin{abstract}
Constant Market Share Analysis (CMSA) is a method which decomposes the variation of market shares of any trader country. The more recent version is proposed by Fagerberg and Sollie that avoids some limits deriving from previously specifications. After explicating how CMSA works, this note presents some applications to the Italian case. Two are the most important contribution of this paper. First, it includes a complete framework on CMSA. Second, the formal derivation of market share variation is proposed.
\end{abstract}

Keywords: Market share; Exports; Trade; Competitiveness; Decomposition

JEL: C00; F00

\section{Introduction}

Constant Market Share Analysis (CMSA) is a way to analyse the international trade of a country. It consists in a technique that decomposes the change in the market share of an exporting/importing country into a series of components and allows identification of the contribution of each component to determine the final result.

In the literature, different versions of CMSA have been formulated, each of which has improved the technique to calculate the various components, which are called "effects".

The original versions proposed by Leamer, Stern [1] and Richardson [2] have some limitations both with respect to the calculation and to the interpretation of the residual component, which affect the reliability of results. The most decisive contribution to the solution of CMSA problems is proposed by Fagerberg and Sollie, who, unlike other authors, make a complete market share decomposition, in the sense that they solve computational problems of previous versions related to the presence of a residual component.

The main contribution of this note is proposing a complete framework on CMSA together with the derivation of the market share decomposition related to the more reliable version from Fagerberg and Sollie $[3,4]$.

The paper is structured as follows: Section 4 summarise the characteristics of the two most important versions of CMSA. Section 5 highlights some applications to the variation of the Italian market share. Section 6 discusses limits of this methodology and section 7 concludes. Finally, the appendix shows the mathematical steps to decomposing the change in market share.

\section{The Technique}

The traditional version has been proposed by Leamer, Stern and Richardson, which decomposes the absolute export change into:

i) A product (or commodity) effect (PE), due to the commodities composition of exports;

ii) A market effect (ME), due to the geographical composition of exports;

iii) A residual component $(\varepsilon)$, which is meant to be the competitiveness effect.

Therefore, the basic relationship between the export change and the three effects is the following:

$$
\Delta \mathrm{X}=\mathrm{PE}+\mathrm{ME}+\varepsilon
$$

where $\mathrm{X}$ indicates total exports to a specific geographical area and $\Delta \mathrm{X}=$ $X_{t}-X_{0}$ is the variation of exports from the period 0 to time $t$.

Starting from this, there have been developments up to the most complete formulation proposed by Fagerberg and Sollie, which aims to tackle the problem related to the calculation of some effects such as residuals (in particular the competitiveness effect), without leading to the demonstration of economic significance. The approach of Fagerberg and Sollie considers the change in market share, rather than the absolute change in exports. It expresses the error $\varepsilon$ in another component. This version presents five effects: in addition to the product and market effects (which are static components), it introduces three dynamic components: the competitiveness effect, the product (or commodity) adaptation effect and the geographical (or market) adaptation effect. The first dynamic component captures the contribution of competitiveness factors to explain the change in market share during a specific period. The two others express information about the country's ability to change the composition of their exports toward products and markets that show expansive trends. Formally:

$$
\Delta \mathrm{Q}=\mathrm{PE}+\mathrm{ME}+\mathrm{PEA}+\mathrm{MEA}
$$

where $Q=\frac{X_{i}}{X_{W}}$ is the market share of a country i toward the rest of the World, $X_{\mathrm{i}}$ the total exports of to the rest of the World and $\mathrm{X}_{\mathrm{W}}$ are the world exports. Then, $\Delta \mathrm{Q}=\mathrm{Q}_{\mathrm{t}}-\mathrm{Q}_{0}$ is the change in export share of a country $\mathrm{i}$ observed between the period $\mathrm{t}$ and the base period 0 . Finally, PE is the product effect, ME is the market effect, $\mathrm{CE}$ is the competitiveness effect and PAE and MAE are the product adaptation effect and the market adaption effect, respectively.

Now, we present the derivation of the five effects, whose mathematical steps are described in Appendix A.

Let be $\mathrm{i}$ the subscript indicating the exporting country; $\mathrm{E}$ the indicator of the concerned geographical area; $h$ is for commodity sectors; $j$ counts the members of the geographical area; 0 indicate the

*Corresponding author: Graziella Bonanno, Department of Economics, Statistics and Finance, University of Calabria, Italy, Tel: +39 0984492474; E-mail: graziella.bonanno@unical.it

Received December 03, 2015; Accepted December 15, 2015; Published December 22, 2015

Citation: Bonanno G (2015) A Note: Constant Market Share Analysis. Int J Econ Manag Sci 4: 302. doi:10.4172/21626359.1000302

Copyright: @ 2015 Bonanno G. This is an open-access article distributed under the terms of the Creative Commons Attribution License, which permits unrestricted use, distribution, and reproduction in any medium, provided the original author and source are credited. 
initial period, $\mathrm{t}$ the final one. Moreover, let be the following vectors and matrices ${ }^{1}$ :

$$
\begin{aligned}
& a_{i j}=\left\lfloor a_{i h j}\right\rfloor \text { is a matrix }(\mathrm{j} \times \mathrm{h}) \text { where } a_{i h j}=\frac{x_{i h j}}{x_{E h j}} \\
& b_{j}=\left\lfloor b_{E h j}\right\rfloor \text { is a matrix }(\mathrm{h} \times \mathrm{j}) \text { where } b_{E h j}=\frac{x_{E h j}}{x_{E . j}} \\
& c=\left\lfloor c_{j}\right\rfloor \text { is a vector }(\mathrm{j} \times 1) \text { where } c_{j}=\frac{x_{E . j}}{x_{E .}} \\
& x_{i}=\left\lfloor X_{i j}\right\rfloor \text { is a vector }(1 \times \mathrm{j}) \text { where } X_{i j}=\frac{x_{i . j}}{x_{E . j}}
\end{aligned}
$$

In particular:

$\mathrm{x}_{\mathrm{ihj}}$ represents the exports of country $\mathrm{i}$ of commodity h toward country j;

$\mathrm{X}_{\mathrm{Ehj}}$ is the exports of the entire area $\mathrm{E}$ of commodity h to country $\mathrm{j}$;

$\mathrm{x}_{\mathrm{E} . \mathrm{j}}$ indicates the total exports of area $\mathrm{E}$ to country $\mathrm{j}$;

$\mathrm{X}_{\mathrm{E} . .}$ represents the total exports of area $\mathrm{E}$;

$x_{i, j}$ is the total exports of country $i$ toward country $j$.

Basically, the matrix elements $\mathrm{a}_{\mathrm{ij}}$ are the ratios of exports of country $i$ to those of the reference area of the $h$ - th commodity to $j$ - th country; therefore, $a_{i h j}$ is the market share for each product of country $i$ (microshare of country $i)$; matrix elements $b_{j}$ are, however, the ratios between exports of the reference area of $\mathrm{h}$ - th commodity and the total exports to the $j$ - th country. They represent the product composition of the markets to which the entire geographical area exports; vector c contains the weights of the exports of each country within the area (the sum of weights is equal to 1 ); vector $x_{i}$ includes, however, the ratios of total exports of country $i$ to those of the reference area to the $j$ - th country and represent the macro-quote.

The market share of country $i$ and its change in period $(0, t)$ are, respectively:

$$
\begin{aligned}
& Q_{i}=\frac{x_{i . .}}{x_{E . .}} \\
& \text { and } \\
& \Delta Q_{i}=Q_{i}^{t}-Q_{i}^{0}=x_{i}^{t} c^{t}-x_{i}^{0} c^{0}=\Delta X_{i}^{a}+\Delta X_{i}^{b}+\Delta X_{i}^{c}+\Delta X_{i}^{a b}+\Delta X_{i}^{x c} \\
& \text { where: } \\
& \Delta X_{i}^{a}=\sum_{j}\left(a_{i j}^{t}-a_{i j}^{0}\right) b_{j}^{0} c_{j}^{0} \quad \text { is the competitiveness effect; } \\
& \Delta X_{i}^{b}=\sum_{j} a_{i j}^{0}\left(b_{j}^{t}-b_{j}^{0}\right) c_{j}^{0} \text { is the product effect; } \\
& \Delta X_{i}^{c}=x_{i}^{0}\left(c^{t}-c^{0}\right) \text { is the market effect; } \\
& \Delta X_{i}^{a b}=\sum_{j}\left(a_{i j}^{t}-a_{i j}^{0}\right)\left(b_{j}^{t}-b_{j}^{0}\right) c_{j}^{0} \text { is the product adaption effect; } \\
& \Delta X_{i}^{x c}=\left(x_{i}^{t}-x_{i}^{0}\right)\left(c^{t}-c^{0}\right) \text { is the market adaption effect. }
\end{aligned}
$$

The first term, namely the competitiveness effect, represents the contribution to the overall variation in market share due to changes in micro-quote $\left(\mathrm{a}^{\mathrm{t}}-\mathrm{a}^{0}\right)$ weighted with the product composition $\left(\mathrm{b}^{0}\right)$ and the market's contributions at initial time $\left(\mathrm{c}^{0}\right)$. It measures the exporting country's ability to penetrate each product market.

${ }^{1}$ The formulation shown in this paper is based on that proposed by Bentivogli and Quintiliani [4].
The product effect is calculated as the change in the commodity composition of export markets $\left(b^{t}-b^{0}\right)$ weighted for the initial microshare $\left(\mathrm{a}^{0}\right)$ and weights $\mathrm{c}^{0}$.

The market effect represents the contribution to the variation of the overall share provided by the changes occurring in the geographical composition of the market $\left(\mathrm{c}^{\mathrm{t}}-\mathrm{c}^{0}\right)$ weighted for the macro-quote of the initial period $\left(\mathrm{x}^{0}\right)$.

The product adaption effect reflects the contribution to explain the change in commodity structure of the exporting country given by the change in micro-quotes $\left(\mathrm{a}^{\mathrm{t}}-\mathrm{a}^{0}\right)$ weighted for the change in product composition $\left(b^{t}-b^{0}\right)$ and the market's contributions at initial time $\left(c^{0}\right)$.

The market adaption effect is the contribution of the variation of the initial macro-quote $\left(\mathrm{x}^{\mathrm{t}}-\mathrm{x}^{0}\right)$ together with the change in the geographical composition $\left(c^{\mathrm{t}}-\mathrm{c}^{0}\right)$.

Appendix A shows the algebra (not in matrix form) for derivation of the competitiveness effect (expression (A2) and, in matrix form, equation (4) of this Section), the structural component (A3), which includes the product (eq. (5)) and market effect (eq. (6)), and the adaption component (A4) (in matrix form, the product adaption effect is shown in eq. (7) and the market adaption effect is in eq. (8) in this Section).

\section{Some Applications to the Italian Case}

CMSA has been used in several studies to assess what are the effects determining the change in the market share of Italian exports. Foresti [5] analyses the dynamics of Italian exports during the Nineties using the approach of Richardson. The conclusions seem to coincide with the expectations. In fact, between 1991 and 1995, the Italian economy performed better than other advanced countries, while in the period 1995 - 2001, the situation is reversed. The results obtained through CMSA imply that the decline in Italian exports observed in the second half of the Nineties is due to unfavourable market and product composition and low competitiveness. This finding is not surprising, because, after 1995, there is a combination of two factors with a negative impact on Italian exports that is the appreciation of the national currency and the entry into the world market of emerging economies with low production costs.

In addition, Finicelli et al. [6] propose an analysis focusing on the period 1985-2003 that includes Italy, United States, Japan, France, Germany, Spain, and some emerging countries such as China and Thailand. From this study, China and other Asian countries show a significant increase in market share, which is due both to the static effects and the strong competitiveness. For countries such as US and Japan, the fact that they are specialised in dynamic industry compensates their loss of competitiveness. The situation is more difficult for Latin America and European countries, characterised by low specialization in high-tech industries and the loss of competitiveness due to the emerging countries [6].

Another important study is proposed by Bentivoglio and Quintiliani that compares the performance of the international manufacturing trade of four Italian regions (Emilia Romagna, Lombardy, Marche and Veneto) through 1992-2002, using the CMSA approach proposed by Fagerberg and Sollie. The two authors show that exports of the regions, together accounting for about $60 \%$ of the national total, have a low technological content, bad for the growth potential of the country. In particular, the lack of specialisation in high-tech industries tends to reduce the development prospects of the country. Through CMSA, 
static factors (i.e., product and market effects) marginally contribute. The paper highlights that the initial structure of regional exports has a low effect in Emilia Romagna and Marche. In addition, for Veneto, the negative impact of the product effect is offset by the positive contribution of the market structure. In Lombardy, the opposite is true. In these cases, the dynamic effects assumes an important role. First, the competitiveness effect is strongly negative for Lombardy, while showing positive values for the other three regions. Secondly, there has been low ability to adapt exports to the global demand for Emilia Romagna, Lombardy and Marche; only Veneto shows a positive value of this component. Finally, Bentivoglio and Quintiliani show that at the end of the considered decade the structure of foreign trade of the four Italian regions continues to be dominated by the made in Italy and the low-tech commodities.

In conclusion, we highlight that application of CMSA is shown in the ICE Report 2008-2009 (Italy in the World Economy), ${ }^{2}$ which shows that Italian exports fell more than the global demand, losing share with respect to emerging countries, to developing countries producers of raw materials and also with respect to the Euro-area countries. In addition, Italian companies face low competitiveness due to an appreciation of the Euro, insufficient growth in productivity and the rise of emerging economies with similar specialisations, but cost structures are more favourable, especially with regard to labour.

\section{Limits of the CMSA}

Although subsequent statements solve some problems related to the calculation and the interpretation of the residual component, the CMSA remains an instrument characterised by strong formal limits.

The crucial point regards the character of identity and not of equation on the basis of the CMSA [7]. Describing an economic phenomenon through an equation means assuming some hypotheses about causal relationships among the variables considered. Therefore, if the model represents the reality well, it is possible to make a prediction of the future values of the same variables. On the contrary, using an identity equation, as in this case, specific conclusions on the future changes of the market share are unpredictable. All this clarifies the purpose description of the CMSA instrument. This method allows a set of synthetic indicators to be obtained from a large set of data describing the evolution of the international trade of an exporting country.

Two problems emerge with strong emphasis from the traditional version of the CMSA due to Leamer and Stern. The first is related to the measure of residual component and the second to the decomposition of the change in the absolute level of exports.

In a subsequent CSMA version proposed by Fagerberg and Sollie, the competitiveness effect is not calculated as residual. However, the applications of CMSA consider this component as an indicator of changes in competitiveness, for example due to relative price changes. The assumption about the competitiveness of a product in international markets according only to the price variations is quite restrictive. It is also determined by key factors, such as the improvement in products quality and other auxiliary services, financial subsidies and also the internal trade policies of a country [7].

As regards the nature of sample data, even using the setting as in most of the literature that consists in elaborations of nominal values, there is a further problem. If nominal shares are considered, a decrease in relative prices can result in a decrease in the share if the elasticity

${ }^{2}$ The acronym ICE stands for "Istituto per il Commercio Estero". of substitution is less to 1 , in absolute value. In this case, the decrease of prices does not involve an expected increase in competitiveness. In particular, this method is not able to separate the effects of prices competitiveness factors from those related to trade reasons.

Dono [8] highlights that the most important limitation of CMSA is to consider demand as an exogenous component. According to the author, also the same exporters help generate demand by activating innovation and product differentiation processes. Therefore, the ability to penetrate the markets cannot be explained only by price competitiveness. At the same time, it is possible that the demand evolution is due to the different policies practiced by the exporter countries.

Richardson also identifies various questions regarding the theoretical foundations, implementation and interpretation of CMSA. According to the author, the choice of the reference area is critical. It should correspond to all the competitors of any exporting country. Another important aspect is related to the influence of different aggregation levels by commodity and geographic location. With regard to the commodity disaggregation, Foresti shows that there are significant differences in the components values. This can be explained with the evidence that groups include products differing in growth rates at a more aggregate level.

Regarding geographical aggregation, some authors highlight the choice of the aggregation industry level as arbitrary and this could lead to potential bias in the components values [9].

Another aspect of criticism is the order of measuring the product and market effects [10]. However this limit exists only in the first formulation of CMSA. The inconvenience is exceeded in the formulation of Fagerberg and Sollie, in which the decomposition is independent of the order by which the effects are calculated.

At these critical points Richardson adds the choice of the weighting system. According to the author, the product and market effects capture the export characteristics in a specific time, without providing information on possible changes in the exports structure. Also in this case, Fagerberg and Sollie propose a solution by using weighting referred to the beginning period through the Laspeyres index.

In particular, the two authors calculate product, market and competitiveness effects as the contribution provided by changes occurring in the commodity and geographical structure and in microshare, respectively, by weighting at the initial time. Moreover, as already highlighted this version introduces two adaption effect (cf. \$2).

In addition, Foresti, Bentivogli and Quintiliani show another analytical problem related to the use of data at current prices or constant prices. As said earlier, if data are used in value and the elasticity of substitution is less than 1 in absolute value, price reductions determine less than proportional increases in the exports. Thus, under these conditions, an improvement of competitiveness could lead to a decrease in exports. Iapadre [11] suggests the use of constant price data to evaluate the effect of price competitiveness on export volumes. The current values, however, would be preferable in some cases, i.e. when the analysis is focused on other aspects than the price like quality, organisation in sale, efficiency of the services connected to the product. However, in almost all studies using CMSA data they are used in current value. Since the major goal of this method is the decomposition of market share, the effect of inflation vanishes at the time of calculating it. 
Finally, Milana shows that the decomposition of identity in mathematical continuous sense has multiple possible versions in discrete sense, therefore it implies an approximation error. In order to reduce this error, the index-number theory suggests building an index related to a period by dividing it into smaller intervals and chaining indices between them. In fact, using the Laspeyres index, Fagerberg and Sollie formalise a more detailed decomposition, which includes also dynamic effects [12].

\section{Conclusions}

CMSA is useful for investigating on a country's exports because it allows to identify the reasons of their failure or growth. In particular, this method permits to distinguish (i) Whether exports are concentrated in commodities for which demand increases or not; (ii) Whether exports are directed to relatively stagnant or dynamic regions; (iii) If country is (un)able to adapt its exports to changes of the economic contest or to competitiveness factors.

This technique has an intensive descriptive but not predictive feature. Therefore, also together with other kind of analysis, CMSA can be used to provide information about a trader's exporting process that ca be interesting for authorities dealing with export policies.

\section{References}

1. Leamer EE, Stern RM (1970) Quantitative International Economics, Aldine Transaction Editor, Allyn and Bacon Inc., Chicago.

2. Richardson JD (1971) Constant Market Share Analysis of Export Growth. Journal of International Economics 2: 227-239.
3. Fagerberg J, Sollie G (1985) The Method of Constant-Market-Shares Analysis Revisited. Central Bureau of Statistics of Oslo, discussion paper No 9.

4. Bentivogli C, Quintiliani F (2004) Technology and dynamic comparative advantages: A comparison of four Italian regions. Nucleus for economic research $1-45$

5. Foresti G (2004) An Attempt to Explain the Italian Export Market Share Dynamics during the Nineties. Centro Studi Confindustria WP No 47.

6. Finicelli A, Sbracia M, Zaghini A (2011) A Disaggregated Analysis of the Export Performance of some Industrial and Emerging Countries. International Economics and Economic Policy 8: 93-113.

7. Mastrostefano M (1998) A few notes in the margin of the Constant Market Share Analysis: theoretical developments and empirical applications in Benedictis MD, Filippis FD (edn.), structure of the agri-food trade and agricultural policy, Franco Angeli, Milan.

8. Dono G (1998) Trade in fresh fruit and vegetables with West Germany application of Constant Market Share Analysis in Benedictis MD, Filippis FD (edn.) Structure of the agri-food trade and agricultural policy, Franco Angeli, Milan.

9. Amador J, Sonia C (2008) The Portuguese Export Performance in Perspective A Constant Market Share Analysis. Economic Bulletin 14: 201-221.

10. Milana C (1988) Constant-Market-Shares analysis and index number theory European Journal of Political Economy 4: 453-478.

11. lapadre LP (1996) Structural factors and competitiveness in international trade: A reworking of the analytical method. Constant -market -shares in processes of internationalization of the Italian economy, CNR, Rome.

12. Rapporto ICE (2009) Italy in the international economy. 